\title{
Improved Steel Beam-Column Connections in Industrial Structures
}

\author{
Nagui William Bishay-Girges \\ Department of Civil Engineering \\ College of Engineering, University of Hail \\ Hail, Saudi Arabia \\ n.bishay@uoh.edu.sa
}

\begin{abstract}
Beam-to-column connection is a rigid connection used in steel moment frames which acts as the main resisting system in structural design. Haunches with double beam section height at the eave, ridge and crane bracket are usually used to resist the large bending moment at the critical locations of the steel frames. Damper devices can be used as the main source of producing forces used to reduce the bending moment due to different static and dynamic loads. This study focuses on improving the steel beam-column connection with the proposed control system in the eave connection which can also be used under the bracket which supports crane beam in industrial buildings. The purpose of this study is to describe the development of the beam-column steel connection incorporating dampers installed to beam bottom flange to reduce the effect of applied load on the frame without the need to create haunches to make the connection design more efficient.
\end{abstract}

Keywords-steel frame; beam-column connection; haunch; bracket; damper; crane

\section{INTRODUCTION}

A structure must be designed and constructed to safely resist the applied loads. The forces applied to a building must be transferred through its structural framework to the building foundation and the supporting ground. This applies to both vertical forces caused by building self-weight and occupancy loads, and the lateral forces caused by winds and earthquakes. To provide a stable structure, the design of the structural framework should provide a complete load path capable of transferring loads from their point of origin to the load-resisting elements. The building must also be designed to resist the overturning effects caused by the lateral forces. Steel structures should be stiff enough to control the drift to prevent structural damage and also must have sufficient ductility to prevent collapse caused by deformation. Portal framed steel structures are the most common type of industrial buildings. They are very efficient and economical when used for single-story buildings provided that the design details are cost effective and the design parameters and assumptions are well chosen. The major components of a portal frame building are a series of parallel portal shaped frames as the major framing elements. Each frame is rigid and resists horizontal lateral forces and gravity loads in the plane off the frame by flexural action in the beams and columns. Beam-to-column connection is a conventional rigid connection in steel moment resisting frame. The columns are generally larger than the rafters because the rafters are haunched near the columns to cater for the peak bending moments at the columns. For the eaves of the portal frame, bolted connections are mostly used of the form shown in Figure 1. A haunch can be created by welding a "cutting" to the rafter to increase its depth locally and to make the connection design more efficient. The cutting is often made from the same steel section as the rafter. In some cases, the column and the haunched part of the beam are constructed as one unit and the constant depth part of the beam is bolted using an end plate connection.

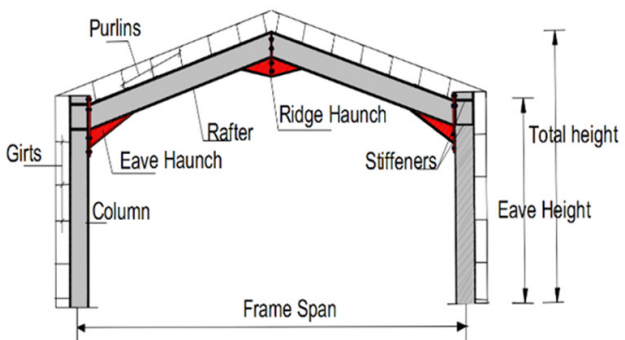

Fig. 1. Steel framed structure with haunches at eave and ridge

In the design of rafters and columns in portal frames the selection of the member sizes may be governed by the ultimate or strength limit state, or by limiting deflections in serviceability limit state. To obtain an economical rafter design, it is important to ensure that the design bending strength is as close as possible to the section capacity which for many sections will be the plastic moment capacity. This capacity is usually achieved by the use of adequate restraints such as fly braces to restrain the inside rafter and lateral column flanges laterally. Rafters are subjected to high bending moments in the plane of the frames which vary from a maximum "hogging" moment at the junction with the column to a minimum sagging moment close to apex. Haunches are used at eaves and apex connections and made from the same sections of beams with a height that equals the depth of frame's beam and a length equal to $10 \%$ of frame's span as shown in Figure 2. In this study, a proposed system using friction dampers called ring springs as bracing system is used to allow a more efficient design, both statically and dynamically. 
(a)

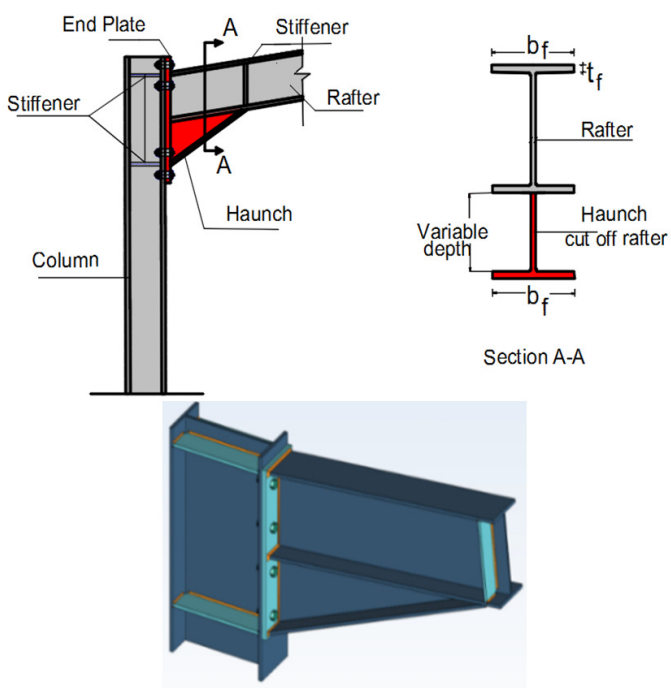

Fig. 2. (a) Eave connection with haunch, (b) prototype of rafter with build-up haunch

\section{BEAM-TO-COLUMN CONNECTIONS}

The detailing of frame connections is probably the most important part of structural design and undoubtedly requires more experience to achieve both sound and economical solutions than does member sizing. Rigid connections transfer significant moments to the columns and are assumed to undergo negligible deformations. Rigid connections are necessary in sway frames for stability and also contribute in resisting lateral loads. In high-rise and slender structures stiffness requirements may warrant the use of rigid connections. According to their stiffness values, connections can be classified as pinned, fully rigid, or semi-rigid. Pinned connections should transmit the internal forces without developing significant bending moments which could affect the connected structural elements. A fully rigid connection presents a high rotational stiffness while semi-rigid connections do not satisfy the criteria for fully rigid or pinned connections [20]. According to the bending moment resistance, a full-strength connection develops a larger capable bending moment than the plastic capable bending moments of the connected elements. Thus, yielding will appear in the weakest structural member connected in the joint [21].

Generally, full strength beam-to-column connections are designed to ensure the plastic hinge formation in the connection or in the beam, thus avoiding plastic deformation is fulfilled by varying the connection components characteristic. Although there are many technical solutions for moment resistant connections, the most frequently used type is the end plate connection with bolts or welding the beam directly to the column. All components of this connection can influence its behavior: the end plate type (exact, extended, or extended with stiffeners), end plate thickness, bolts diameter, the compression or tension stiffeners on the web panel of the column, and the shear stiffeners on the web panel of the column as shown in Figure 3. (a)

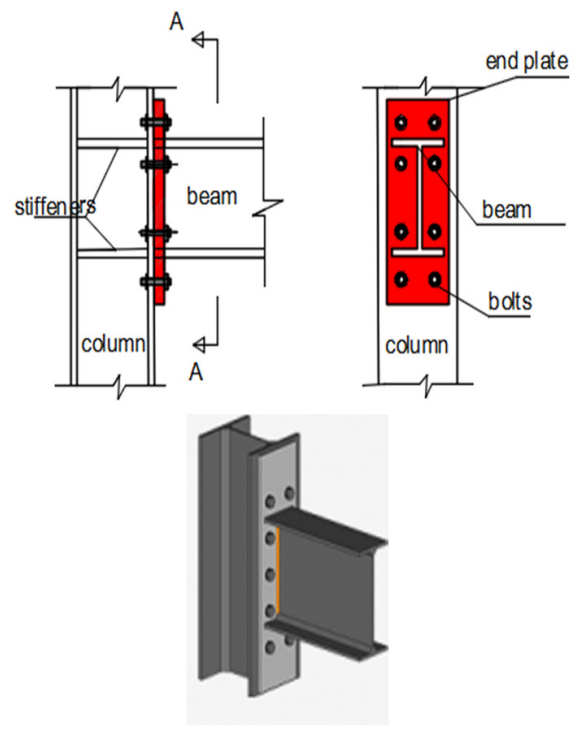

(c)

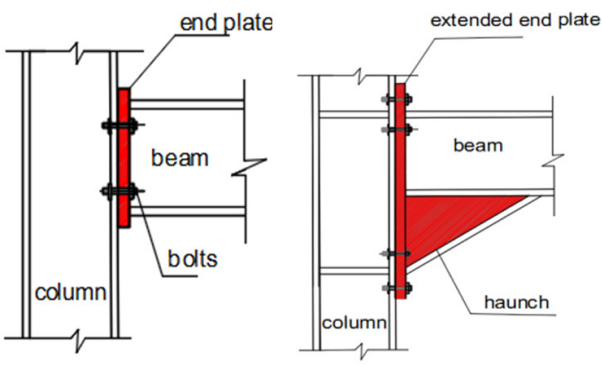

Fig. 3. Rigid beam-to-column connections: (a) flushed short end plate and haunch beam-column connection, (b) connection prototype, and (c) extended end plate and section A-A

Moment connections are designed to transfer bending moments, shear forces and sometimes normal forces. The design strength and stiffness of a moment connection are defined in relation to the strength and stiffness of the connected members. The design strength of a moment connection may be full-strength (i.e. the moment capacity of the connection is equal to or large than the capacity of the connected member) or partial-strength (i.e. the moment capacity of the connection is less than that of the connected member). Similarly, the stiffness of a moment connection can be rigid or semi-rigid compared to the stiffness of the connected member. The rotation capacity of the structure may be provided by either the connection or the connected member. Deformation capacity is usually provided by plastic deformation of one or more components. If the strength of the connection clearly exceeds the strength of one of the connected members, the designer can rely on the deformation capacity coming from the connected, e.g. the formation of a plastic hinge in the beam. After the mechanical properties of all components have been determined, the various components can be assembled to determine the strength, stiffness, and deformation capacity of the whole connection. The bending moment of the beam is primarily taken by the flanges in the form of tension and compression forces. The bending moment of the column is also resolved as a force couple. Stiffeners help in distributing the forces in the 
connection zone and in avoiding local repture, crushing or buckling of the beam web.

\section{PREVIOUS RESEARCH}

Considerable research has been carried out to improve the beam column connections in resisting the applied loads and deflections [2-14]. A different method of a steel yielding damper in the beam-to-column connections relying on the combination of slit damper and T-stud is proposed in [2] as shown in Figure 4, with an aim to increase energy dissipation capacity and stiffness and to reduce lateral damage on the structure. The purpose of this method is to develop a connector which works as a key energy-absorbing device in beam-to column joints. The idea of combining a T-stud and steel slit dampers is utilized and a damper is formed via embedding slit segments within the flange of the connector. It is expected that plastic deformation to be concentrated on connectors, while the main structural components remain elastic.
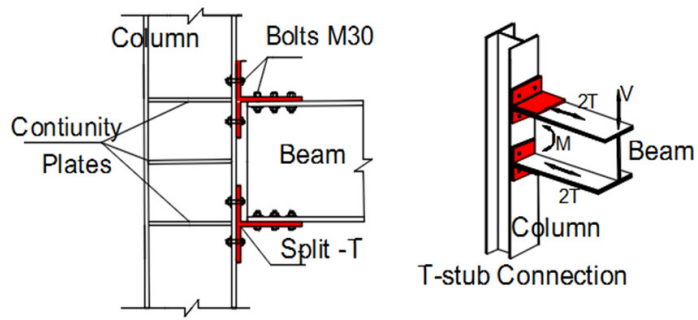

Fig. 4. T-stud connection

Another research in developing the beam to column connections used cast high-strength steel brackets that fastened to each beam flange and bolted to the column flange as shown in Figure 5 [3]. The brackets are proportional to develop the full moment capacity of the beam and can be either welded or bolted to the beam flange. When subjected to large lateral deformation, the connection forces yield and plastic hinge formation occurs in the beam, beyond the tip of the brackets and away from the column face.
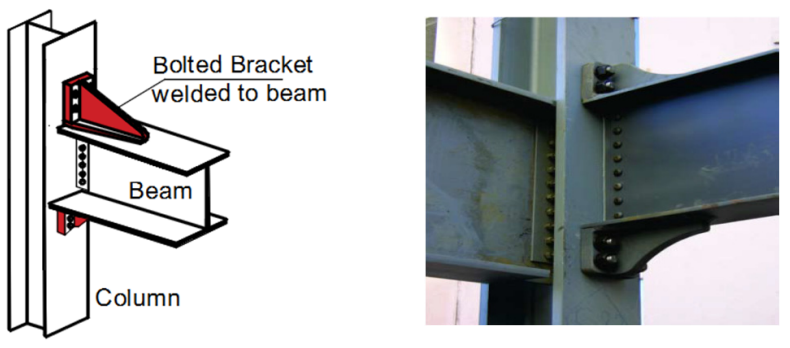

Fig. 5. Bolted bracket and typical connection

Authors in [4] presented beam to column connections equipped with super elastic shape memory alloy tendons as recentering elements and shear tabs or web hourglass steel pins as supplementary energy dissipating and shear resisting components (Figure 6). Connecting the beam web to the column flange, shear tabs can help transfer shear force from the beam to the column. Moreover, friction between shear tab and beam web can enhance the energy dissipation capacity of the connection.

(a)

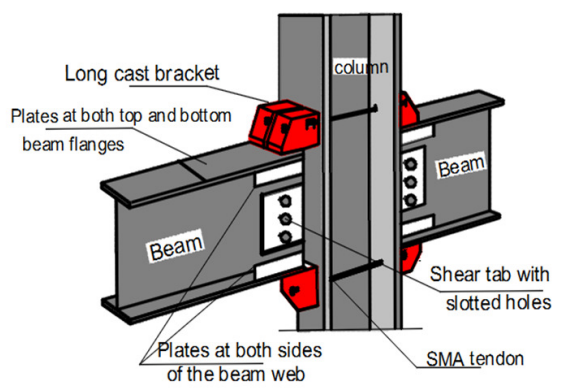

(b)

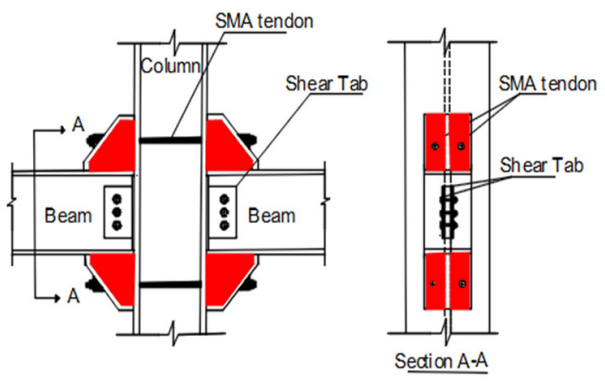

Fig. 6. (a) Typical tendon connection, (b) beam-to-column connection with shape alloy tendons

Connections incorporating shape memory alloy tendons outside the beam flanges feature a significantly higher amount of moment capacity and initial stiffness as this configuration provides a longer lever arm for the tendon-bearing force couple. Changes in the amount of resisting forces produced by the energy dissipating devices could greatly affect the cycle behavior of the connection in terms of strength, stiffness, energy dissipation and recentering ability. The Sliding Hinge Joint (SHJ) connection [5] is a low damage alternative to the traditional beam column welded connections of the Moment Resisting Steel Frame (MRSFs). The sliding hinge joint connection is intended to behave as a rigid beam-column connection under the Serviceability Limit State (SLS) condition. Under the ULS condition, the SHJ is expected to allow large beam to column inelastic relative rotation through stable sliding in its key energy dissipating components i.e. the Asymmetric Friction Connections (AFCs).
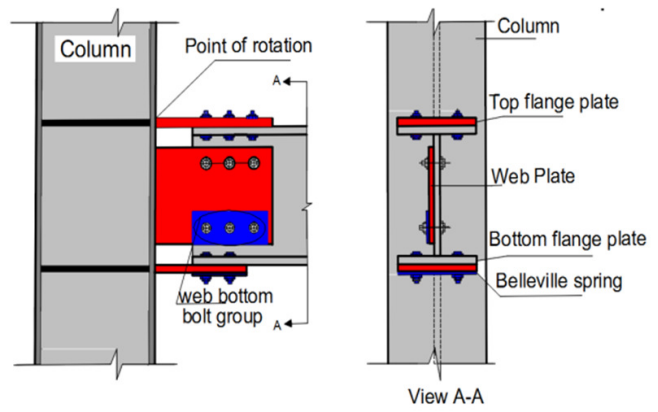

Fig. 7. The Sliding Hing Joint Connection (SHJ) 
The AFCs are located at the bottom web and bottom flange bolt groups as shown in Figure 7. A top flange plate is bolted to the beam top flange, and the SHJ point of rotation is where this top flange plate is pinned to the column. The moment-relative rotation behavior of the SHJ is dependent on and schematically similar to the AFC force-displacement behavior. When subjected to an increasing bending moment, the SHJ initially behaves like a rigid beam-column connection until the moment in the beam end exceeds the frictional resistance of the bottom web and bottom flange. When this occurs, the beam rotates relatively to the column about the point of rotation, through sliding in the AFCs while dissipating energy through friction sliding. The main benefits to the SHJ are isolating the floor slab to limit additional demands to the beam, column, and slab under inelastic rotations; and confining yielding to the bolts.

\section{PROPOSED BEAM COLUMN CONNECTION SYSTEM}

This study produces a new system that can be used to connect beams and rafters to steel columns in industrial steel buildings subject to a combination of gravity and lateral loads [18]. This system is used for the large span steel frames [16-19] required haunches in the eaves to increase the capacity of the beam section to resist the large bending moment at the eave in the steel frame $[20,21]$. The haunch in the eave of the frame can be replaced by a damper device that can produce damping forces to reduce bending moment, thereby reducing the cross section of the rafter with haunch as shown in Figure 8. The damper is fixed at the bottom flange of the beam or rafter by using a couple of plates welded to the beam and column flanges. The device can be relatively small and in the same configuration to the bottom flange of the haunch. Stiffeners may be used in the beam and column webs at the location the damper is connected. The end plate is not needed to extend more than the height of the beam rafter.
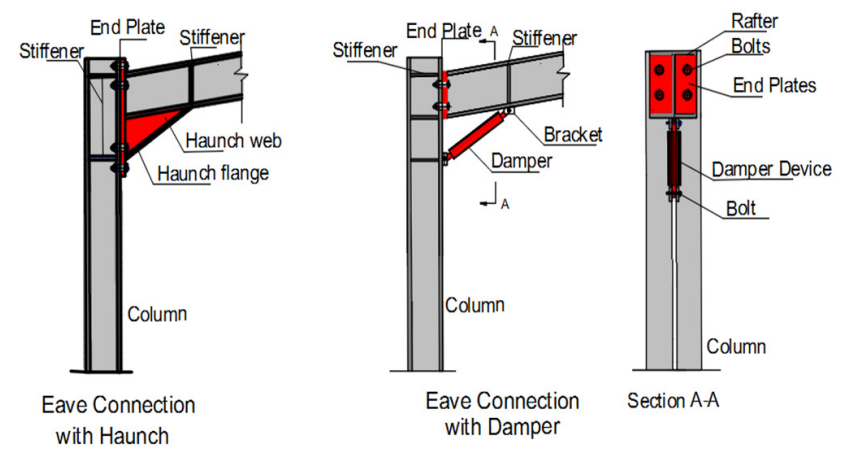

Fig. 8. Beam-column connection with damper

The damper device that can be used in this case is the ring spring damper. This passive control system provides a selfcentering friction mechanism. The damper consists of inner and outer rings that have tapered mating surfaces. Under the application of axial compression load, the wedge action of the taper faces causes the inner elements to radially contract and the outer elements to radially expand, allowing axial deflection as shown in Figure 9. This sliding action between mating elements results in a large amount of energy being absorbed in overcoming the friction forces. When applying load to a preloaded system, sufficient force must be applied to the ring springs for the motion to proceed along the stiffness path from point 0 to point 1 . That force is to overcome frictional resistance before sliding action within the ring spring commences. This gives rise to an elastic stiffness between points 0 and 1 . As load is increased, displacement continues between points 1-2. During the next phase of displacement unloading proceeds between points 2-3 and then continue to point 4 , returning to the origin. This motion is repeated when the direction of the loading / unloading is reversed as shown in Figure 10.

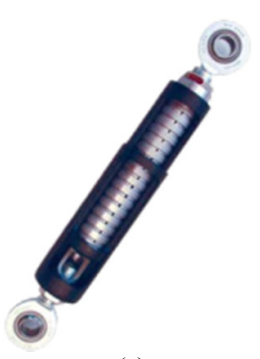

(a)

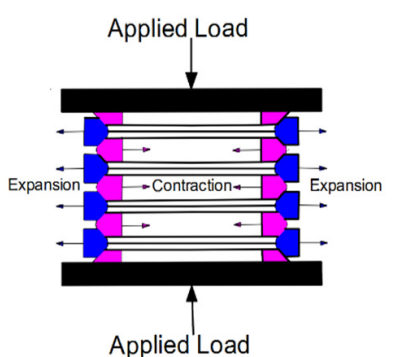

(b)
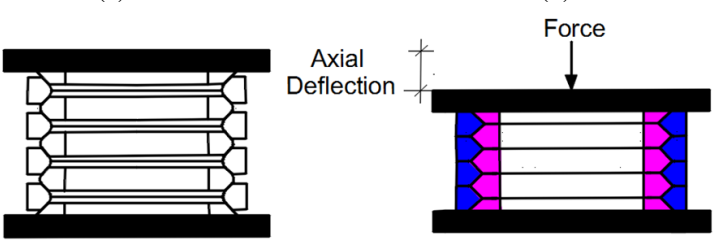

(c)

Fig. 9. Ring springs damper properties: (a) Ring spring prototype, (b) loaded ring springs fully compacted, (c) deflection of friction springs

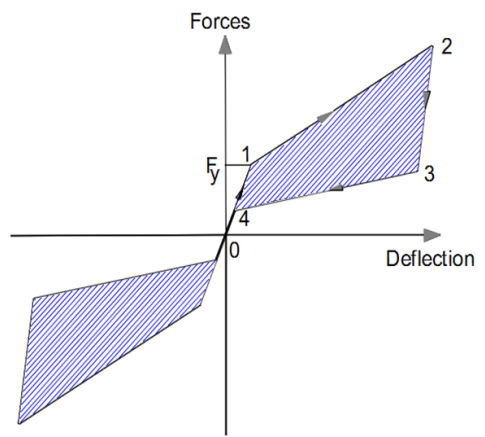

Fig. 10. Double acting hysteresis diagram of ring spring dampers

To illustrate the benefits of the proposed system in reducing the bending moment at the eave connection, a $25 \mathrm{~m}$ span with $6 \mathrm{~m}$ eave height is used for a steel frame applied to a vertical load equals to $20 \mathrm{kN} / \mathrm{m}$. The cross section of both steel columns and rafter was selected to be universal steel section 360UB50. As shown in Figure 11, the maximum bending moment at the eaves of the frame is equal to $795 \mathrm{kN} . \mathrm{m}$ [15]. The shown bending moment is obtained without using haunch at the eaves of the frame. In conventional steel structures, in order to resist large values of bending moment, the rafter should be provided by a haunch at the eaves to increase the leaver arm of the rafter and section capacity. By adding haunches in the eave 
connection, the additional stiffness of the haunches will change the horizontal reaction which in turn will influence the eave and ridge moments. The percentage increase in bending moment in eave connections ranges from 2 to $3 \%$. In this case, the eave bending moment will be equal to $815 \mathrm{kN} . \mathrm{m}$. With the proposed system using dampers at the eaves to produce control forces to resist the applied loads, the bending moment of the beam rafter is reduced significantly. Figure 12 shows the bending moment for the frame structure using damper devices rather than haunches in the eaves. The force produced in the damper is $100 \mathrm{kN}$ and the bending moment at the eave reduced to $272 \mathrm{kN}$ decreasing to $65 \%$. In this case, the $360 \mathrm{UB} 50$ section is a cable to resist the reduced bending moment without increase the section of the beam rafter by using haunch.

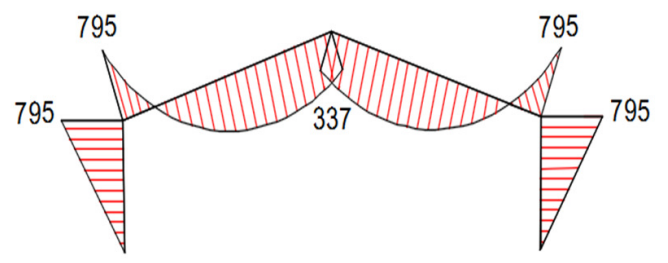

Fig. 11. Bending moment of the steel frame without haunch

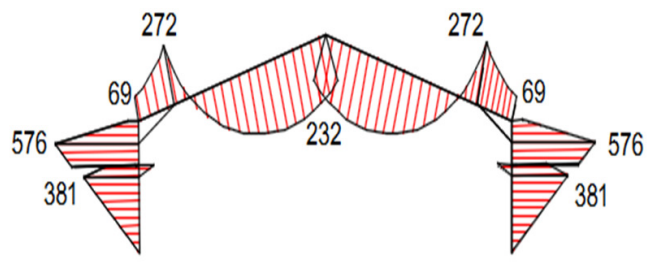

Fig. 12. Bending moment of the steel frame with the proposed damper

\section{CRACE BRACKETS IN INDUSTRIAL BUILDINGS}

Bridge cranes are used for handling in large workshops and storage and industrial buildings, usually working under the roof, and if necessary, in the open. They move by two parallel rails placed along the length of the hall. The main parts are the bridge and the driving winch, which moves along the bridge.

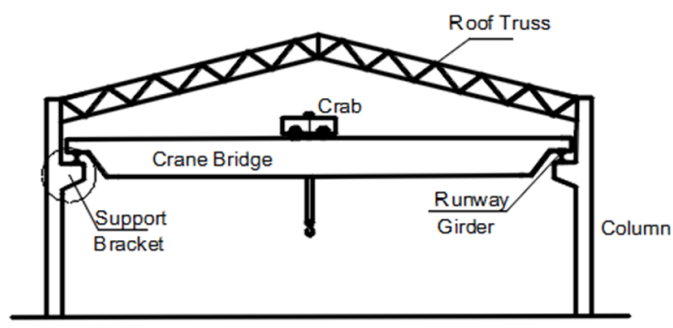

Fig. 13. Industrial trussed frame structure with crane

The crane bridge moves on the rails and the driving winch carts move across the bridge to transport from one place to another within the working range of the crane as shown in Figure 13. In industrial buildings with crane, the crane girders are supported either on brackets connected to columns of uniform section or on stepped columns. Brackets are used for lighter crane loads as shown in Figure 14, and the stepped columns for heavy cane loads. The proposed system can also be used in industrial buildings with cranes. Due to the significant impact of the wheel load of the moving crane on the crane rail, a haunch connected to the bracket is required to resist the vertical and horizontal applied load. The haunch of the bracket is fixed to the steel frame column by a steel plate using high tensile steel bolts welded to the bracket. Instead of using the steel haunch, the damper device is installed on the column-bracket as a control system to reduce the impact of the applied load and enables the bracket section to carry the load. The damper device is installed under the crane bracket as shown in Figure 15. Figure 16 shows the difference between the bending moment of the frame without and with the damper devices. The reduction in the bending moment of the frame is about $23 \%$. The advantages of using the proposed system are the easy installing to the crane bracket and the effective reduction of the internal straining forces in frame structure.

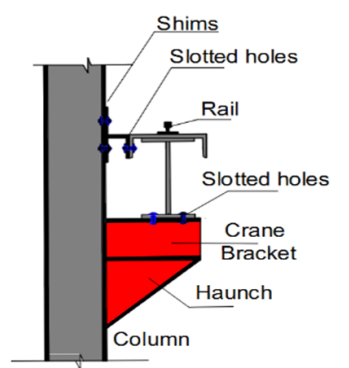

Fig. 14. Support bracket connection
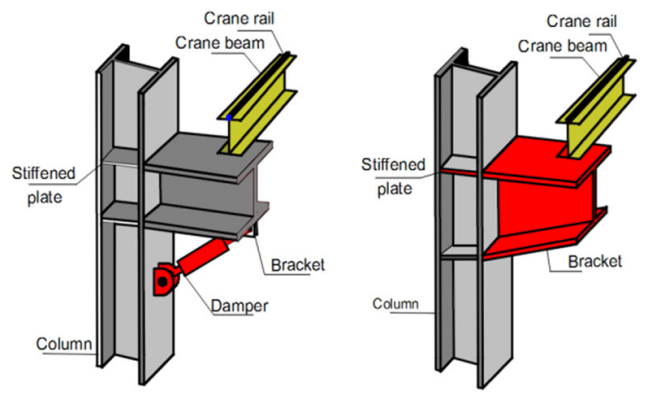

Fig. 15. Crane bracket with damper and haunch

(a)

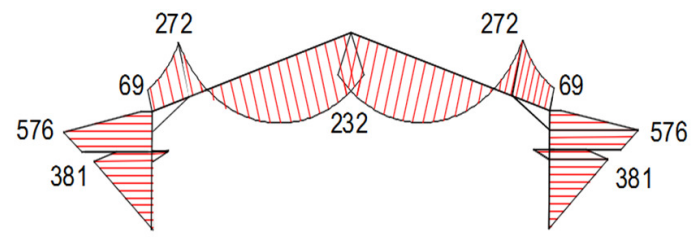

(b)

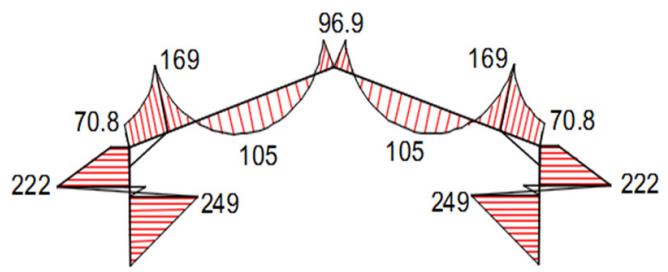

Fig. 16. Bending moment diagram (a) without damper system at the crane bracket, (b) with damper system at the crane bracket 
The results of the numerical analysis showed that the proposed system improves beam-column connection behavior either at the eaves or at the crane bracket column connections.

\section{CONCLUSION}

This study describes an improvement of the steel beam-tocolumn connections in frame industrial buildings. The beamcolumn connection is considered and acts as the main load resisting system in the structural design. Several previous researches in developing beam-to-column were presented and different connection forms were shown. In conventional connections, haunches are used to increase the capacity of the steel beam to resist the applied loads. An alternative system to the conventional connection using dampers is proposed. Friction ring spring dampers are attached beneath the bottom flange of the beams and fixed to the flange of the column rather than increasing the depth of the cross section of the beams by haunches. The proposed system can be used at the critical connections of the steel frame such as the eave and crane bracket connections of the high values of the bending moments. Dampers are used to produce the control system to reduce the bending moment of the applied load on the frame sections. The proposed system offers advantages such as: a) simplified installing to the bottom of the beams and columns, b) the possibility of increasing the control system produced by the damper to reduce the bending moment. With the proposed system there is no need to increase the depth of the beam height by welding haunches of cutoff of the beam section and increase the end steel plate to resist the high bending moment at the critical connections. In order to assess the behavior of the proposed system in industrial buildings, the model of a steel frame without and with the system was carried in Microstran [11] and analyzed. Two analysis groups with the dampers at eaves and bracket column connections were investigated. The percentage of reduction in the bending moment varied between $65 \%$ and $23 \%$ in eave and crane bracket connections respectively. The structure behavior was evaluated and the results indicated that the bending moments at the critical connections have been significantly reduced by the installation of the proposed system.

\section{ACKNOWLEDGEMENTS}

The author wishes to express his gratitude to Professor Athol J. Carr for his suggestions and help.

\section{REFERENCES}

[1] New Zealand Standard, AS/NZS 1170.2 (2002): Structural design actions, part 2: Wind actions, New Zealand Standard, 2002

[2] K. Bayat, B. Shekatehband, "Seismic performance of beam to column connections with T-shaped slit damper", Thin-Walled Structures, Vol. 141, pp. 28-46, 2019

[3] P. P. Cordova, R. O. Hamburger, "Steel connections: Proprietary or public domain?”, Modern Steel Construction, Vol. 10, pp. 24-31, 2011

[4] M. A. Farmani, M. Ghassemieh, "Steel beam-to-column connections equipped with SMA tendons and energy dissipating devices including shear tabs or web hourglass pins", Journal of Constructional Steel Research, Vol. 135, pp. 30-48, 2017

[5] S. Rambormozian, G. C. Clifton, G. A. MacRae, H. H. Khoo, "The sliding hinge joint: Final steps towards on optimum low damage seismic-resistant steel system", Key Engineering Materials, Vol. 763, pp.751-760, 2018
[6] T. J. Mander, G. W. Rodgers, J. G. Chase, J. B. Mander, G. A. MacRae, R. P. Dhakal, "Damage avoidance design steel beam-column moment connection using high-force-to-volume dissipators", Journal of Structural Engineering, Vol. 135, No. 11, pp. 1390-1396, 2009

[7] G. Machae, C. Clifton, "Low damage design of steel structures", Steel Innovations 2013 Workshop, Christchurch, New Zealand, February 2122, 2013

[8] J. M. Fisher, Design guide 7 industrial buildings: roofs to anchor rods, American Institute of Steel Construction, 2005

[9] C. Christopoulos, A. Filiatrault, C. M. Uang, B. Folz, "Posttensioned energy dissipating connections for moment-resisting steel frames", Journal of Structural Engineering, Vol. 128, No. 9, pp. 1111-1120, 2002

[10] S. R. Mirghaderi, M. D. Renani, "The rigid seismic connection of continuous beams to column", Journal of Constructional Steel Research, Vol. 64, No. 12, pp. 1516-1529, 2008

[11] J. M. Ricles, R. Sauce, M. M. Garlock, C. Zheo, "Posttensioned seismicresistant connections for steel frames", Journal of Structural Engineering, Vol. 127, No. 2, pp. 113-121, 2001

[12] C. C. Chou, Y. C. Wang, J. H. Chen "Seismic design and behavior of post-tensioned steel connections including effects of a composite slab", Engineering Structures, Vol. 30, No. 11, pp. 3014-3023, 2008

[13] J. N. Arlekar, C. V. R. Murty, "Improved truss model for design of welded steel moment-resisting frame connections", Journal of Structural Engineering, Vol. 130, No. 3, pp. 498-510, 2004

[14] M. Wolski, J. M. Ricles, R. Sause, "Experimental study of a selfcentering beam-column connection with bottom flange friction device", Journal of Structural Engineering, Vol. 135, No. 5, pp. 479-488, 2009

[15] Microstran Leading-edge Software for Structural Engineers, Product data sheet, Bentley

[16] P. H. Sarjou, N. Shabakhty, "Effect of the improved pall friction damper on the seismic response of steel frames", Engineering, Technology \& Applied Science Research, Vol. 7, No. 4, pp. 1833-1837, 2017

[17] G. Xu, M. Yamanari, "Performance of steel frame with linkage system under earthquake excitation", Engineering, Technology \& Applied Science Research, Vol. 9, No. 1, pp. 3795-3801, 2019

[18] N. W. B. Girges, "An alternative system for eccentrically braced frames resisting lateral loads", Engineering, Technology \& Applied Science Research, Vol. 9, No. 3, pp. 4281-4286, 2019

[19] A. Williams, Steel structural design for lateral and vertical forces, Mc Graw Hill, Second edition, 2016

[20] S. T. Woolcook, S. Kitipornchai, M. A.Bradford, Design of portal frame building, Australian Institute of Steel Construction, Third edition, 1999

[21] B. E. Gorenc, R. Tinyou, A. A. Syam, Steel designers' handbook, UNSW Press, Eighth edition, 2012 